\title{
REVIEW
}

\section{Neurovisual rehabilitation: recent developments and future directions}

\author{
Georg Kerkhoff
}

Central visual $^{1}$ and oculomotor ${ }^{2}$ disorders are present in some $20 \%-40 \%$ of patients in neurological rehabilitation centres. ${ }^{3}$ Gianutsos reported that $50 \%$ of the patients in a head trauma rehabilitation centre show visual system disorders not assessed before although most of the patients were chronic and had been treated in other hospitals previously. ${ }^{4}$ In a large sample of 314 patients with postchiasmatic visual field disorders from a rehabilitation department $70 \%$ had a parafoveal visual field sparing of $5^{\circ}$ or less. Of these patients, $50 \%-70 \%$ subjectively reported and objectively showed chronic reading and visual exploration deficits. ${ }^{5}$ Furthermore, visual field disorders are associated with an adverse prognosis in outcome studies according to life table analysis ${ }^{6}$ and impair the success of vocational rehabilitation. ${ }^{4}$ Spatial-perceptual deficits may delay the rehabilitation progress in physiotherapy, ${ }^{8} 9$ lead to complications due to repeated accidents, ${ }^{10}$ and correlate highly with deficits in activities of daily living (dressing, transfers, or manoeuvring a wheelchair. ${ }^{11-16}$

In the presence of limited financial resources in health policy it might be argued that central visual disorders do not require treatment as they do not affect outcome adversely. Although nothing supports this opinion there is some evidence to the contrary. Cutting inpatient stroke rehabilitation to a maximum of 60 days (in Italy) led to a deterioration in neuropsychological and activities of daily living in patients with stroke, especially those with right hemispheric lesions. ${ }^{17}$ Hence, withdrawing neuropsychological treatment deteriorates functional performance and creates new costs. Whereas the systematic treatment of language, speech, and motor disorders is traditionally viewed as unequivocally necessary the possible influence of visual-sensory and oculomotor disorders on the patient's outcome is still neglected in neurorehabilitation. This review summarises therapeutic approaches for acquired central visual disorders. It is split into five parts. After an introduction into the role of vision in neurorehabilitation, the second part deals with current theorising of recovery from brain damage, cortical plasticity, and implications for rehabilitation. Part three summarises low level and high level visual disorders after brain lesions and their resulting impairments. In part four therapeutic approaches for these disorders are detailed, where available. In the last part, future perspectives for neurovisual rehabilitation including new experimental, but unexplored approaches are outlined. Pharmacological stimulation efforts ${ }^{18}$ and disorders of the anterior visual pathways are not covered. Visual neglect is only alluded to in the section of future directions, to indicate new promising treatment techniques that might be relevant for other visual disorders as well (see Robertson ${ }^{19}$ for a recent, excellent review on neglect rehabilitation).

\section{Why rehabilitate neurovisual deficits?}

Common sense usually associates visual acuity, colour, and depth perception with the general term "vision", and this very limited understanding of visual capacities, the resulting visual impairments, and consequences for daily life after an acquired brain lesion are often found in professional neurorehabilitation teams as well. A closer look at different visuoperceptual and oculomotor abilities required for cognitive and motor abilities in a neurorehabilitative context is given in fig 1 .

According to this more elaborate view visual functions are relevant for four main types of activity: for the patient's mobility, for binocular vision and depth perception, for reading, and for subsequent language processing. Finally, vision is one of the major input channels to memory, and the most important medium in the workplace in our visually and PC dominated world. Consequently, impairments in one or several visual capacities that contribute to these purposes will lead to deficits in non-visual activities (cognition and motor control). If this multifaceted view of vision is adopted in a rehabilitation context, treating visual deficits is not only interesting in itself, but has an important impact on the patient's rehabilitation progress in other, non-visual treatment areas. Two examples illustrate this: a patient with head trauma with a deficit in convergent fusion has a severely limited span for reading and PC work (in the order of $10 \mathrm{~min}$ utes, see later). If this remains untreated vocational rehabilitation will probably fail as reading and PC work are an essential part of such programmes. Alternatively, consider a secretary with hemianopic alexia due to a right 


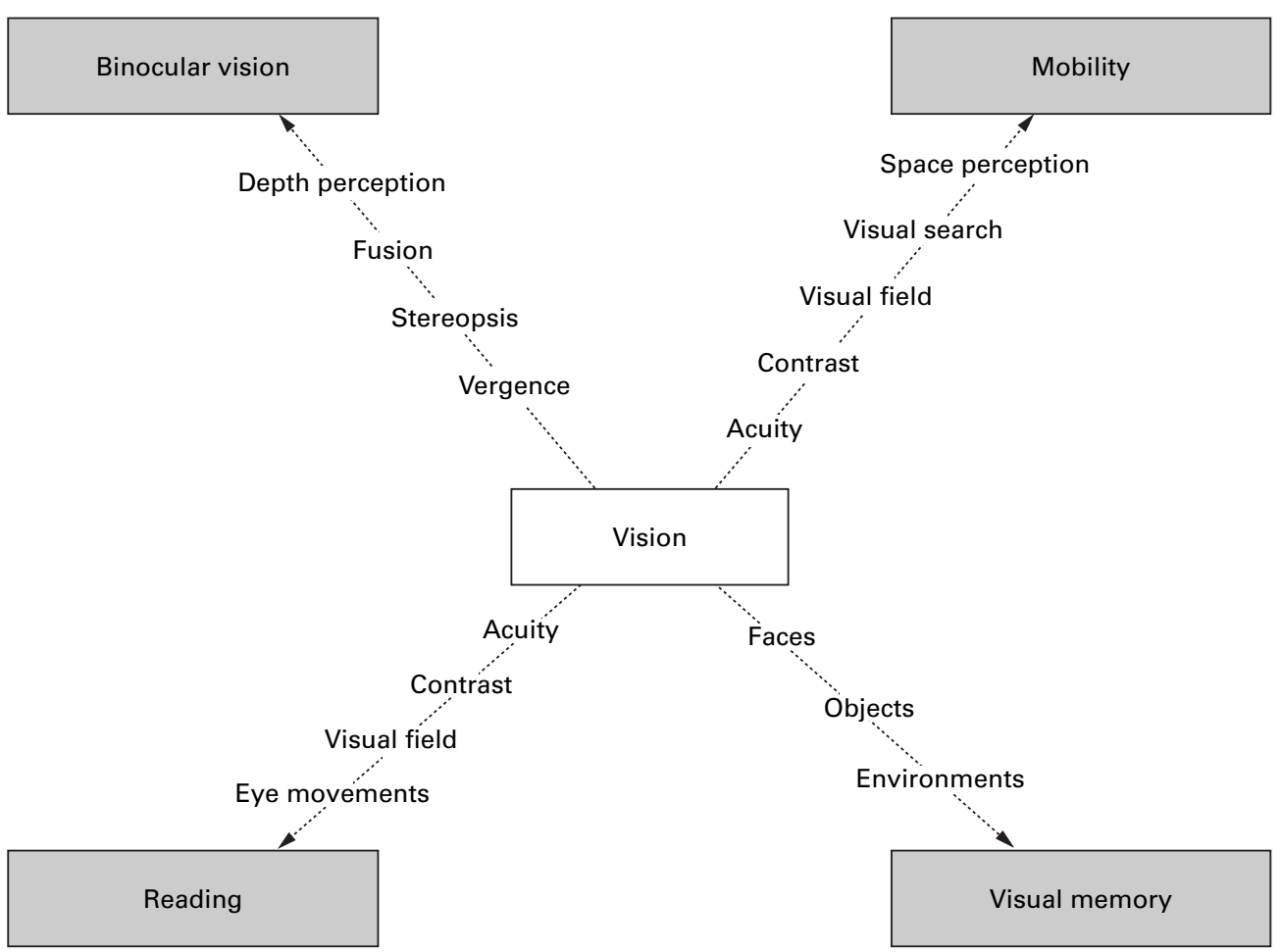

Figure 1 Relevance of different visual abilities for four main types of activities (binocular vision, reading, mobility, visual memory) in a neurorehabilitative context. Visual abilities contributing to a certain type of activity are listed along the arrows. No attempt was made to list all abilities possibly contributing to a certain type of activity.

sided, fovea reaching hemianopia $\left(2^{\circ}\right.$ field sparing; see later). As long as her reading speed remains $1 / 5$ of her premorbid level, reading will be so laborious for her, that few cognitive resources remain to understand and memorise what she has read. Furthermore, memory training based on written material will probably be unsuccessful as well.

\section{Recovery from brain damage and brain} plasticity: implications for rehabilitation Traditional thinking of neurologists and neuropsychologists about recovery from acquired brain damage is usually that lost neurons in the brain cannot regenerate, so that-due to the relatively fixed mapping of functions to certain brain areas - the boundaries for neurorehabilition are firmly set. ${ }^{20}$ As a consequence, restorative approaches have been used only with limited success in visual rehabilitation (see Kerkhoff ${ }^{5}$ for a more detailed discussion). Most often treatments for neurovisual disorders try to utilise intact functions (compensation), use or try to develop optic and prosthethic devices, or aim at improving the adaptation of the environment to the patient's impairment (substitution). Nevertheless, there are approaches for direct retraining of an impaired function (restitution) - that is, perimetric visual field training or the training of convergent fusion (see fig 3).

However, the traditional thinking concerning the brain's very limited capacity for reorganisation after a lesion in adulthood has been changing in the past few years. ${ }^{19}$ This is for two reasons: firstly, it has been shown recently in animals and humans that some degree of neurogenesis is possible in adulthood (see McMillan et $a l^{20}$ for further details); secondly, neurogenesis ${ }^{21}$ and representational cortical changes ${ }^{22}$ are both experience dependent, and therefore might be enhanced by specifically tailored rehabilitation programmes. The critical point in the next few years will therefore be to evaluate if such plastic changes in an injured brain can lead regenerated neurons to acquire normal or near to normal functions, and more importantly, if this has a significant impact on the improvement of day to day visual functions. In support of such a more optimistic view of the rehabilitation potential after brain lesions Buonomano and Merzenich ${ }^{22}$ recently concluded "...that cortical maps are dynamic constructs that are remodeled in detail by behaviourally important experiences throughout life (p150)", and "...that the cortex reorganises its effective local connections and responses following peripheral or central alterations of inputs and in response to behavior." (p150). If this view of neuroplasticity is only partially justified it should be possible in the next few years to develop new or improve existing treatments that exploit this lifelong potential for cortical/ subcortical reorganisation after central lesions. Even if no functional restitution can be achieved - for example, due to a large cortical lesion-some degree of cortical reorganisation or plasticity is probably required for the acquisition of new compensatory strategies. Hence, learning compensatory sacadic eye movements to a blind hemifield to cope with the field loss (see below) probably necessitates cortical reorganisation in oculomotor brain centres (to generate the eye movements towards the scotoma) and in cortical regions representing 
Table 1 Survey of frequent visual and oculomotor disorders, their aetiologies, anatomical localisation of the lesion and resulting impairment and disabilities

\begin{tabular}{|c|c|c|}
\hline Deficit & Aetiology and localisation of lesion & Impairment/disability \\
\hline Visual acuity (near/far) & $\begin{array}{l}\text { Primary deficits: bilateral or unilateral postchiasmatic } \\
\text { lesion(s); Secondary deficits: eccentric fixation in cerebral } \\
\text { hypoxia, visual exploration deficits, disturbed } \\
\text { simultaneous perception and spasmodic fixation } \\
\text { (Balint/Holmes syndrome) }\end{array}$ & $\begin{array}{l}\text { Impaired object identification and reading, near work } \\
\text { fatigue }\end{array}$ \\
\hline Contrast sensitivity (spatial, temporal) & $\begin{array}{l}\text { Unilateral, bilateral, and diffuse "posterior" brain lesions; } \\
\text { temporal for high spatial and parietal for low spatial } \\
\text { frequencies }\end{array}$ & $\begin{array}{l}\text { Blurred vision; recognition of objects, traffic signs, } \\
\text { distances or faces impaired at low luminance }\end{array}$ \\
\hline Adaptation (photopic, scotopic) & $\begin{array}{l}\text { Posterior thalamic or "posterior" brain lesions, cerebral } \\
\text { hypoxia, occasional severe head injury }\end{array}$ & $\begin{array}{l}\text { Blinding/dark or foggy vision; delayed/lost adaptation to } \\
\text { different luminance levels; eye strain, impaired depth } \\
\text { estimation, reduced acuity, asthenopic disorders }\end{array}$ \\
\hline Stereopsis and depth perception & $\begin{array}{l}\text { V2 lesions: local stereopsis; temporal lesions: global } \\
\text { stereopsis; parietal lesions: } 3 \text { D stereo features of objects; } \\
\text { right hemispheric preponderance }\end{array}$ & $\begin{array}{l}\text { Slowed and inaccurate grasping and manipulative } \\
\text { movements, impaired depth perception, reduced reading } \\
\text { duration }\end{array}$ \\
\hline Convergent fusion & $\begin{array}{l}\text { - Vergence movements: midbrain lesions } \\
\text { - Sensory fusion: impaired after V2 and/or } \\
\text { temporoparietal lesions }\end{array}$ & $\begin{array}{l}\text { Reading difficulties, reduced visual sustained attention in } \\
\text { near work conditions, somatic complaints (eye strain) }\end{array}$ \\
\hline Homonymous visual field disorders & $\begin{array}{l}\text { PCA infarctions, bleedings, cerebral hypoxia, along the } \\
\text { whole course of the postchiasmatic visual pathways }\end{array}$ & $\begin{array}{l}\text { Impaired visual search/orientation in } 2 \mathrm{D} \text { and } 3 \mathrm{D} \text { space, } \\
\text { reading difficulties, slowed and inaccurate performance in } \\
\text { functional visual activities }\end{array}$ \\
\hline Visual-spatial perception & $\begin{array}{l}\text { Dorsal visual pathways and basal ganglia after MCA } \\
\text { lesions, more frequent and more severe after right } \\
\text { cerebral lesions }\end{array}$ & $\begin{array}{l}\text { Disturbed perception of geometric relations: subjective } \\
\text { visual vertical and horizontal, impaired orientation and } \\
\text { localisation performance }\end{array}$ \\
\hline Visual object and face recognition & $\begin{array}{l}\text { Bilateral/sometimes unilateral right PCA lesions or } \\
\text { cerebral hypoxia along the ventral visual stream }\end{array}$ & $\begin{array}{l}\text { Recognition of objects and faces under unconventional } \\
\text { viewing conditions or non-optimal lighting conditions }\end{array}$ \\
\hline Balint/Holmes syndrome & $\begin{array}{l}\text { Bilateral MCAs of the parietal or frontal branches or } \\
\text { bleedings; diffuse lesions in both hemispheres due to } \\
\text { cerebral anoxia, encephalitis, trauma, degenerative } \\
\text { diseases }\end{array}$ & $\begin{array}{l}\text { Impairments in: visual fixation, reading, grasping, visual } \\
\text { search, simultaneous perception, depth and space } \\
\text { perception }\end{array}$ \\
\hline Eye movement disorders & $\begin{array}{l}\text { (a) large MCA infarctions parietotemporal; more } \\
\text { frequent right }\end{array}$ & $\begin{array}{l}\text { (a) Conjugate, tonic imbalance of both eyes to the } \\
\text { ipsilesional side; inability to fixate/reach for } \\
\text { objects/persons in the contralesional hemispace; }\end{array}$ \\
\hline (a) Conjugate eye deviatons & $\begin{array}{l}\text { (b) Unilateral superior temporoparietal lesions after } \\
\text { MCA infarctions or trauma with brain stem damage }\end{array}$ & $\begin{array}{l}\text { hypometric saccades and increased saccadic latencies for } \\
\text { saccades to the contralesional hemispace; impaired } \\
\text { smooth pursuit towards ipsilesional hemispace; }(b)\end{array}$ \\
\hline (b) Smooth pursuit & & $\begin{array}{l}\text { difficulties following moving objects/vehicles/persons, } \\
\text { omissions of critical objects; impaired orientation during } \\
\text { self motion of person }\end{array}$ \\
\hline
\end{tabular}

the blind hemifield on an abstract, non-visual level (to generate a space map on which eye movements can operate). According to this logic all rehabilitation strategies (restitution, compensation, substitution) require an adaptive nervous system that enables the patient to adapt to cerebral visual impairments, either spontaneously or by specific treatments. The degree and type of the required cortical plasticity is likely to differ between these three main strategies, probably being much higher for restitutional changes in a local area of a lesion, whereas probably more widespread processes of reorganisation are required for the acquision of new strategies to enable compensation or substitution. Another prediction from neuroplasticity research is that cortical plasticity should be higher in "higher", especially multisensory, brain regions ${ }^{23}$ and accordingly lower in "early" visual areas. For neurovisual rehabilitation this means that restitution after lesions to the primary visual cortex (area V1 or 17) is probably much more restricted than that after lesions to higher (temporal, parietal) visual areas in the processing chain. We return to some of these ideas when discussing the treatment approaches.

\section{VISUAL ACUITY}

Static visual acuity is normal after unilateral postchiasmatic lesions. ${ }^{24}$ However, clinical experience has shown that it may be partially reduced in the early phase after a brain lesion by $20 \%-30 \%(0.2-0.3$ Snellen) due to reduced contrast sensitivity (see later), disturbed visual search, inaccurate fixation, or impaired simultaneous perception in Balint's syndrome (table 1). These secondary deficits in visual acuity result from other impairments. After bilateral postchiasmatic lesions Frisén ${ }^{24}$ has described primary reductions in visual acuity ranging up to cerebral blindness (defined as a visual acuity $<2 \%)$. Cerebral blindness is frequent in patients with cerebral hypoxia due to cardiac $\operatorname{arrest}^{2526}$ or bilateral occipital lesions presumably affecting the foveal visual field representation in both hemispheres. ${ }^{27}$ The acuity loss in these cases is comparable in both eyes, as are the accompanying field defects. In a recent large scale study of 454 patients with and without postchiasmatic scotomata ${ }^{5}$ it was found that two types of visual field disorders are particularly associated with reduced visual acuity for the near $(0.4 \mathrm{~m})$ and far $(6 \mathrm{~m})$ distance: bilateral homonymous hemianopia and bilateral hemiamblyopia (impaired colour and form discrimination in homonymous field regions). Both groups together accounted for some $12 \%$ of patients with visual field disorders. The reductions in visual acuity ranged from $10 \%$ $80 \%$ in the sample, and were probably chronic as lesion age was 35 weeks on average. ${ }^{5}$ Reduced visual acuity impairs reading and mobility (as illustrated in fig 1).

Lesions of one optic tract lead to reduced static visual acuity in the ipsilesional eye, or in both eyes. ${ }^{28} 29$ An asymmetric impairment of visual acuity in both eyes after posterior brain lesions indicates optic nerve or chiasmal lesions. ${ }^{24}$ So far, static visual acuity was consid- 
ered (with stationary optotypes and a sitting observer). However, in everyday life the identification of moving vehicles or persons is often required as we, as well as our surroundings, are continually moving. Although rarely tested, this dynamic visual acuity is impaired by deficits in smooth pursuit eye movements, ${ }^{30}$ or nystagmoid fixation instability. ${ }^{18}$ In healthy, aged adults dynamic visual acuity is more impaired than static acuity, which causes problems in identifying moving objects in the visual periphery. $^{31}$

\section{CONTRAST SENSITIVITY}

Contrast sensitivity denotes the ability of the visual system to discriminate between striped patterns (gratings) of differing luminance (contrast) and stripe width (spatial frequency). Such patterns can either be presented as stationary (spatial contrast sensitivity) or as drifting patterns on a monitor (temporal contrast sensitivity). Abnormalities in spatial and temporal contrast sensitivity occur after postchiasmatic lesions. ${ }^{32}$ The patients complain about blurring of vision and deficits in reading, when recognising objects or faces especially under mesopic or scotopic lighting conditions. $^{33}$ Some of these patients also indicate an increase in subjectively required lighting for near work activities (reading, writing, PC work, and technical and household activities; G Kerkhoff, unpublished results). Deficits in different spatial frequency channels are associated with different visual problems: high frequency losses are related to impaired visual acuity whereas low frequency losses are probably interfering with distance and depth perception (for example, ascending a dimly lit staircase, reading a distant sign). Patients with impaired contrast sensitivity often have normal or close to normal visual acuity as tested with high contrast optotypes ${ }^{34}$ so that their contrast sensitivity deficit may go undetected. By contrast, with the relatively rare reductions in visual acuity after unilateral postchiasmal lesions (apparently $12 \%{ }^{5}$ ), spatial contrast sensitivity is more often impaired (apparently $82 \%{ }^{35}$ ), at least in patients with acute lesions.

PHOTOPIC AND SCOTOPIC FOVEAL ADAPTATION Photopic foveal adaptation denotes the ability of the visual system to adapt continuously to a higher illumination whereas scotopic foveal adaptation describes the ability to adapt to a darker illumination than the present one. (Photopic and scotopic foveal adaptation, as defined in the present context, is not to be confused with light or dark adaptation which reflects the photochemical activity of cones and rods in the central and peripheral retina, respectively. This kind of adaptation is mainly impaired in patients with retinal or optic tract lesions but probably remains unimpaired in postchiasmatic lesions with intact anterior visual pathways.) Deficits in both processes were described already 50 years ago in occipital lobe lesions. ${ }^{36}$ However, they are not well recognised and present a significantly underestimated visual problem in patients with brain damage. Both disorders can occur separately or in combination. ${ }^{37}$ In this study ${ }^{37}$ a large unselected sample of 116 patients with postchiasmatic lesions was examined; $51 \%$ were found with a loss of scotopic and photopic adaptation, $26 \%$ with an isolated disorder of photopic adaption, and $23 \%$ with impaired scotopic adaptation.

The most frequent aetiology is unilateral or bilateral posterior cerebral artery infarctions, and here most likely those of the mediobasal branches originating from the posterior thalamus. $^{38}$ Cerebral hypoxia ${ }^{37}$ and head trauma ${ }^{39}$ often cause a combined adaptation disorder. Furthermore, patients with head trauma may show an increased sensitivity to light and sound..$^{40}$ Patients with a reduced or lost foveal photopic adaptation complain about "blinding" and describe frequent changes in lighting as unpleasant (for example, when leaving a room and walking outside; when looking at a white wall or a white sheet of paper). Patients with an impairment in foveal scotopic adaptation complain about "dark vision" and need more light during near work. In a combined disorder (which seems implausible, but exists in some $30 \%$ of patients ${ }^{37}$ ) the patients complain about blinding and dark vision and have a very small range where lighting is comfortable form them (100 lux $v 1000$ lux in normal subjects ${ }^{37}$ ). Spontaneous recovery is absent or extremely rare, although the patients behaviourally adapt to the disorder ( $G$ Kerkhoff, unpublished results).

\section{STEREOPSIS}

Stereoscopic vision can be divided into local versus global stereopsis. Local stereopsis requires the extraction of disparity cues from a few visual elements in a display (for example, the Titmus test). Global stereopsis requires the ability to extract a global form from many disparity signals present in a complex visual display (the TNO test ${ }^{41}$ ). Deficits in local stereopsis have been found in patients with unilateral or bilateral posterior cerebral lesions, especially those affecting the secondary visual cortex (V2; layer 4C), and are more frequent and more severe in patients with right sided cerebral lesions (see Rizzo ${ }^{41}$ for review). Reductions in global stereopsis have been described in patients with left or right sided temporal lobectomy, ${ }^{42}{ }^{43}$ without hemispheric differences. Recent findings from functional brain imaging ${ }^{44}$ and monkey neurophysiology ${ }^{45}$ suggest that different stereoscopic abilities are represented in different brain areas according to the functional specialisation of that particular area. Accordingly, the parietal cortex is involved in the stereoscopic coding of three dimensional object characteristics (depth and longitudinal axis of an object ${ }^{45}$ ). Little is known about the recovery from astereopsis, and no follow up studies have been carried out to my knowledge. It remains to be mentioned that some $5 \%-10 \%$ of healthy subjects show astereopsis as a result of squint. ${ }^{41}$ Two thirds of the patients with impaired convergent fusion (see later) show reduced stereopsis, too. ${ }^{46}$ 
CONVERGENT FUSION

As we perceive our visual world with two eyes which supply us with a slightly disparate image, the two images have to be fused into one "cyclopean" image. Fusion requires a motor component ${ }^{47}$ to direct the eyes to a target either further away than the present fixation point (divergent fusion or crossed disparity) or nearer by (convergent fusion or uncrossed disparity). Convergence and divergence are represented in different brain stem nuclei. ${ }^{48}{ }^{49}$ The second component is a non-motor, sensory act of unifying the two visual images, called sensory fusion. Impairments in both components are rarely examined but are strikingly frequent in patients with closed head injury..$^{50-53}$ It can be estimated on the basis of the above mentioned studies that some $30 \%$ of patients with head trauma initially show reduced convergent fusion. Hart ${ }^{53}$ noted that spontaneous recovery was poor or almost absent in his patients. Given the frequency of fusional disorders and their importance for near work, stereopsis, reading, and vocational rehabilitation, it is surprising that few systematic studies have so far dealt with their diagnosis and treatment. The possible effects of fusional disorders on other activities, especially visuomotor behaviour (grasping, walking, distance estimation) are largely unexplored. However, clinical experience suggests that fusion and vergence eye movements are important for near work

A

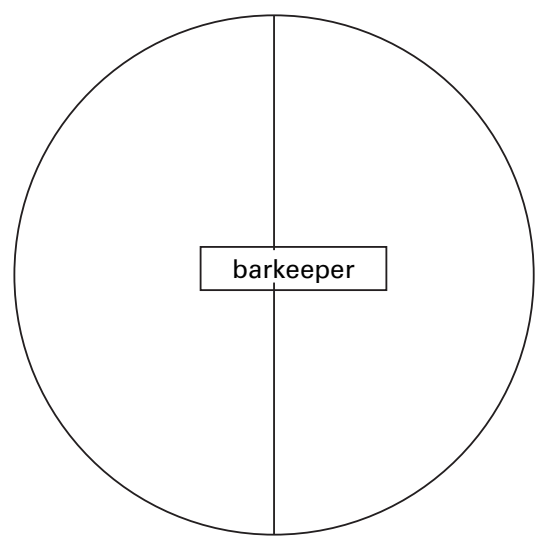

C

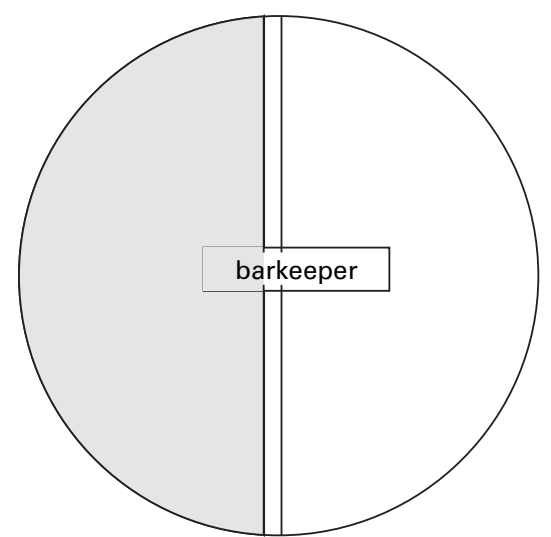

(fig 1), when establishing gaze contact in social interactions and possibly in visuomotor activities in near space.

HOMONYMOUS VISUAL FIELD DISORDERS

About $20 \%-30 \%$ of all patients in neurological rehabilitation centres have homonymous visual field disorders. ${ }^{3}$ Among these, $70 \%$ show a visual field sparing of $5^{\circ}$ or less. ${ }^{15}$ About $7 \%$ of all patients with cerebrovascular infarctions develop cerebral blindness with a variable degree of residual visual capacities. ${ }^{27}$ Cerebral blindness often occurs in children with cerebral hypoxia with slow and incomplete recovery. ${ }^{54}$ Furthermore, patients with visual field disorders from traumatic brain lesions show substantial cognitive deficits due to diffuse disseminated lesions. ${ }^{55}$

Partial field recovery occurs in the first 2-3 months in $10 \%-20 \%$ of the patients. ${ }^{56}$ After this period spontaneous field recovery is very rare. If it occurs it is greater in peripheral than in parafoveal regions due to the cortical magnification factor. ${ }^{56}$ Patients with visual field disorders face visual behavioural problems that fall into two categories: hemianopic reading deficits due to the parafoveal field loss and abnormal saccades during reading,${ }^{57}$ and visual exploratory deficits in the blind and intact hemifield $^{58}$ due to small amplitude saccades, ${ }^{59}$ and spatially disorganised visual search patterns ${ }^{60}$ and a narrowed useful field of view

B

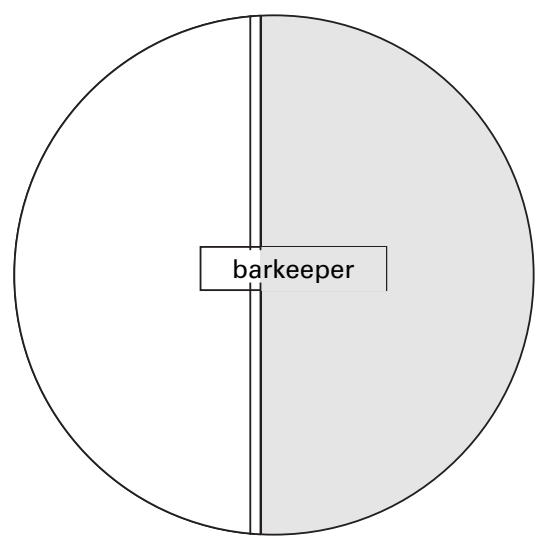

D

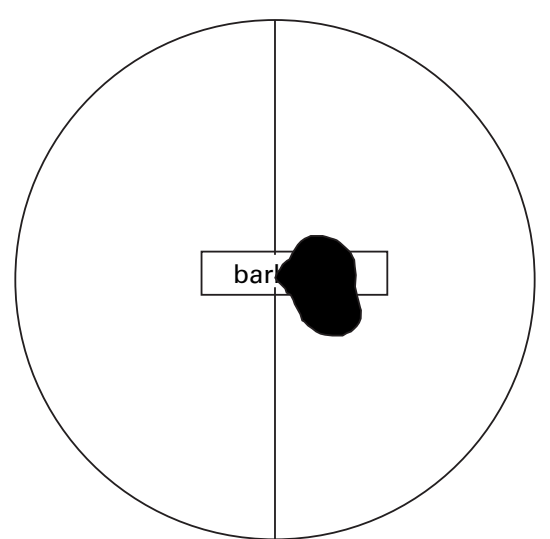

Figure 2 Schematic display of the perceptual window for reading $(A)$ in a normal subject, $(B)$ a patient with a homonymous, left sided hemianopia (field sparing: $2^{\circ}$ ), and $(C)$ a patient with a homonymous, right sided hemianopia (field sparing: $\left.2^{\circ}\right) ;(D)$ right sided, homonymous paracentral scotoma (between $2^{\circ}-15^{\circ}$ eccentricity on the right horizontal meridian). Note that the drawings are schematic and not drawn to scale. 
also in the ipsilesional hemifield. ${ }^{61}$ This leads to omissions of critical targets or their delayed detection in both the blind and intact hemifield. Some $50 \%-90 \%$ of all patients with visual field disorders have hemianopic alexia, ${ }^{62}$ resulting from the loss of parafoveal field regions which form a "perceptual window" for reading, subserving letter identification. In western societies this reading window extends 3-4 characters to the left of fixation and 7-11 letter spaces to the right of it. ${ }^{63}$ Figure 2 schematically illustrates this perceptual window and the differential effects of left or right sided hemianopia and a right sided paracentral scotoma on reading. Due to the asymmetry of the perceptual window right sided visual field disorders cut a larger part of the reading window and therefore impair reading more than left sided visual field disorders. Moreover, left sided visual field disorders cause mainly errors (omissions of the left words or syllables) whereas right sided visual field disorders reduce reading speed significantly. ${ }^{5}$

\section{VISUOSPATIAL PERCEPTION}

Visual space perception is important for mobility and orientation in the environment. Impairments in the perception of the subjective visual vertical and horizontal, orientation discrimination, length, size, and position discrimination are often found in lesions of the parieta $l^{64}$ or parieto-occipital cortex and underlying white matter. ${ }^{65}$ Patients with neglect with right parietal lesions have visuospatial deficits as well. ${ }^{62}$ Right hemispheric lesions cause more frequent impairments in elementary spatial perception. ${ }^{65-67}$ Significant recovery from visuospatial deficits has been described previously ${ }^{68}$ but this could have been influenced by retest effects. Spontaneous recovery occurs to most in the first 3 months, ${ }^{69}$ after which no further improvement is seen. Visuospatial deficits predict a negative patient outcome, ${ }^{14}$ increased probability of accidents, less transfer of physiotherapeutic training to walking, ${ }^{8}$ and dressing problems. ${ }^{15}$ Hence, visuospatial deficits are of prognostic value, especially in patients with lesions in the right hemisphere.

VISUAL OBJECT AND FACE PERCEPTION

Disorders in the recognition of objects and faces are rare, and often, though not necessarily, coupled with low level visual deficits (acuity, visual fields, visual exploration, simultaneous perception ${ }^{70}$ ). Visual recognition disorders can be categorised into apperceptive and associative disorders. Patients with apperceptive recognition disorders are found after bilateral temporo-occipital lesions, either bilateral occlusions of the posterior cerebral artery or lesions of degenerative, hypoxic, or infectious origin (herpes encephalitis). ${ }^{71}$ Such patients still have largely intact knowledge of the semantic properties of objects (for example, their use, size, colour, and weight) but are impaired in the visual recognition of them, especially under demanding visual conditions (for example, poor lighting conditions or an unusual view). By contrast, patients with associative visual agnosia are capable of visually recognising objects but have lost semantic knowledge or have impaired access to the semantic properties of visually presented objects. $^{71}$

Disorders in the perception of faces are found after unilateral right sided or bilateral occipitotemporal lesions. ${ }^{72}{ }^{73}$ Patients with face agnosia say that faces look strange and lack emotionality and familiarity. They do not recognise familiar faces, especially under conditions of poor lighting or from an unusual viewpoint. Recovery is probably very limited in cases with bilateral or diffuse disseminated lesions. Anderson and Rizzo ${ }^{74}$ described permanent deficits in the facial recognition test ${ }^{75}$ in $25 \%$ of their patients. Even less is known about the treatment of such disorders apart from a few single cases. ${ }^{76}$

BALINT'S OR HOLMES' SYNDROME AND RELATED DISORDERS

Balint's syndrome designates a poorly defined category of symptoms including: impaired fixation of gaze, defective visually guided reaching, especially in contralateral hemispace, impaired simultaneous perception of more than one or a few objects, reading inability, defective depth perception, and severe visuospatial disorders. ${ }^{77} 78$ Due to the bilateral or diffuse disseminated lesions recovery is limited in these severely and chronically disabled patients. It is estimated that some $30 \%$ of patients with Alzheimer's disease show the full range of Balint's syndrome, ${ }^{79}$ but the inciddence in non-dementing, neurological disease is probably less than $0.5 \%$ (G Kerkhoff, unpublished results). Reports on rehabilitation techniques are rare ${ }^{80}$ It is likely that the disorder is often overlooked or misdiagnosed. Eye blinking may eliminate confusing visual images or the patient's subjective feeling of seeing the same object at multiple locations in space. Zihl and Kennard noted some recovery of visual exploration and fixation after systematic training in three patients with Balint's syndrome, ${ }^{70}$ but no recovery of the spatial disorder. Despite these occasional experiences effective treatment strategies are poorly developed and evaluated.

EYE MOVEMENT DISORDERS

A comprehensive review of acquired eye movement disorders is beyond the scope and aim of this review. ${ }^{81}$ Instead, two types of eye movement disorders that interact with neurovisual rehabilitation are described.

\section{Conjugate eye deviation}

Conjugate eye deviation occurs in acute hemispheric brain lesions as a type of tonic imbalance of both eyes towards the lesioned hemisphere at rest. It is more frequent after right hemispheric lesions $(30 \%-50 \%)$ than in patients with left hemispheric lesions $(20 \%){ }^{82} 83$ Parietal cortex and basal ganglia lesions seem to be critical for conjugate eye deviation..$^{83}$ It lasts longer in patients with right cerebral lesions (mean 65 days) than in those with left cerebral lesions (mean 17 days $^{84}$ ), although this probably depends on lesion size 


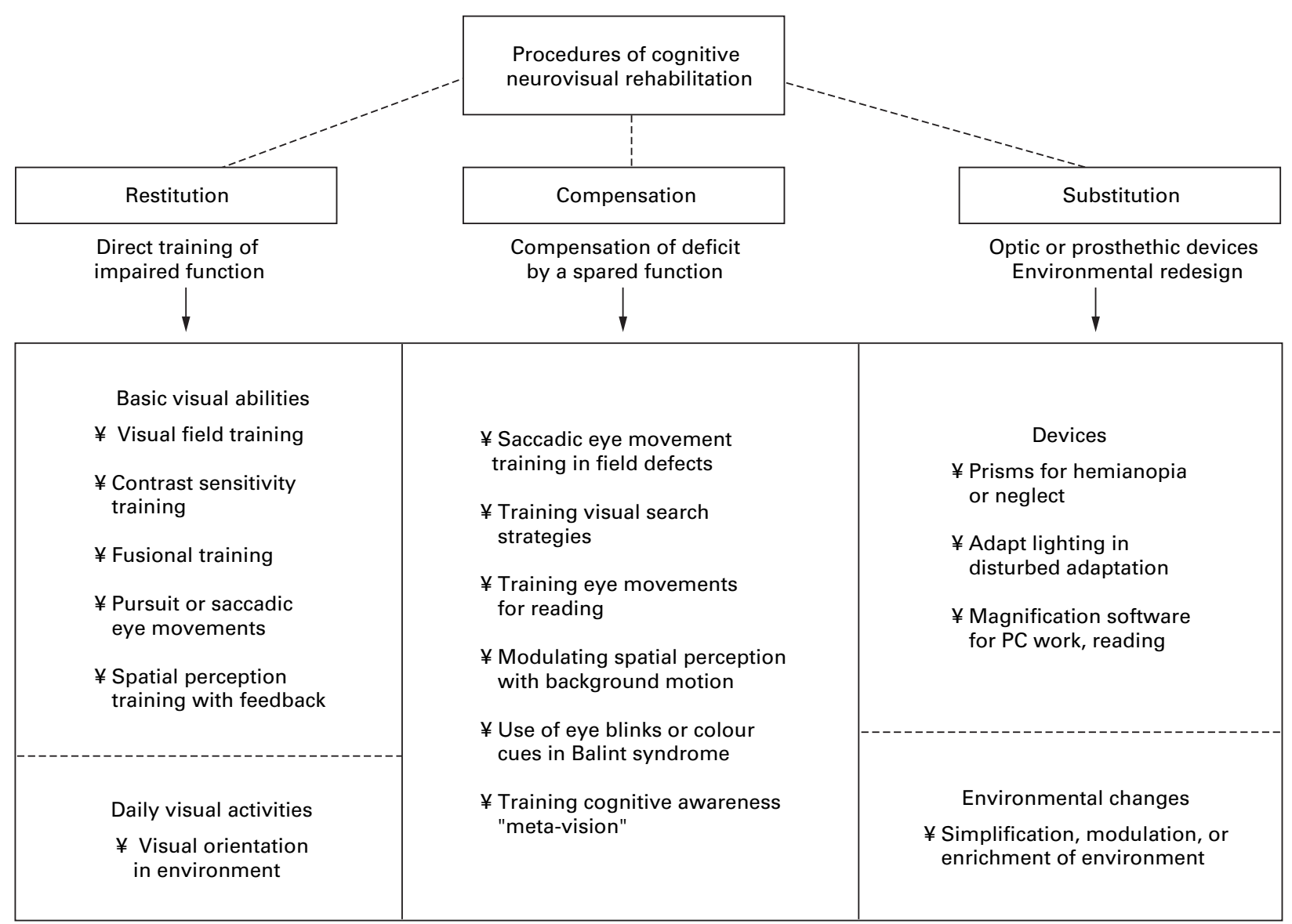

Figure 3 Survey of procedures used in neurovisual rehabilitation. See text for details.

and location. Conjugate eye deviation and visual neglect often occur together, enhancing each other. Even after apparent recovery of conjugate eye deviation the patients show hypometric saccades towards the contralesional hemispace, higher saccadic latencies, and a reduced smooth pursuit gain when tracking objects moving towards the ipsilesional hemispace. ${ }^{84}$ This tonic ocular imbalance almost certainly has a negative impact on all rehabilitation efforts (physiotherapy, self care activities, mobility, activities of daily living, reading, and visual exploration). After recovery of the overt conjugate eye deviation it can be reinstated by the simultaneous presentation of two objects in both hemifields $\left(\right.$ extinction ${ }^{85}$ ), the eyes drifting towards the lesioned hemisphere.

Smooth pursuit disorders

Smooth pursuit disorders are found in patients with brain stem, ${ }^{86}$ unilateral parietal, parietooccipital, frontal eye field, ${ }^{87-89}$ and cerebellar lesions. ${ }^{30}$ They impair the tracking of an object moving in an ipsilesional direction (from left to right in a patient with a right hemispheric lesion), even with low stimulus velocities $\left(<20 \% \mathrm{~s}^{30}\right)$. Patients with head trauma ${ }^{90}$ and patients with focal brain lesions ${ }^{30}$ have a considerably reduced smooth pursuit gain $(<0.5$ or $50 \%$ of their normal value) which causes deficits in dynamic visual acuity and vocational tasks-for example, work on PC monitors. ${ }^{90}$ A reduced pursuit gain reduces dynamic visual acuity ${ }^{30}$ and therefore impairs visuospatial orientation and identification of moving objects (persons, vehicles) in daily life.

\section{Treatment approaches}

As mentioned earlier, treatment approaches can occur on three main levels (restitution, compensation, and substitution; fig 3). These levels do not exclude each other, and in some instances (for example, saccadic eye movement training in hemianopia, fig 3, middle column) a treatment may be considered as restorative and compensatory at the same time; as it improves compensation and leads to partial field recovery, and hence might be considered "restitutive" as well. Figure 3 categorises most of the visual treatment approaches described in detail later in the appropriate sections.

\section{VISUAL ACUITY}

Restorative approaches to improve impaired static visual acuity after postchiasmal lesionsapart from the always obligatory objective refractometry-have not been published to my knowledge. Although optical correction often does not enhance acuity in patients with postchiasmatic lesions, various methods to improve acuity indirectly are useful (table 2). In clinical experience, these secondary deficits are often easier to modulate than primary reductions of static visual acuity. Eccentric or unsteady fixation, visual exploration deficits, reduced simultaneous perception, and im- 
Table 2 Summary of treatment approaches for patients with postchiasmatic visual acuity impairments

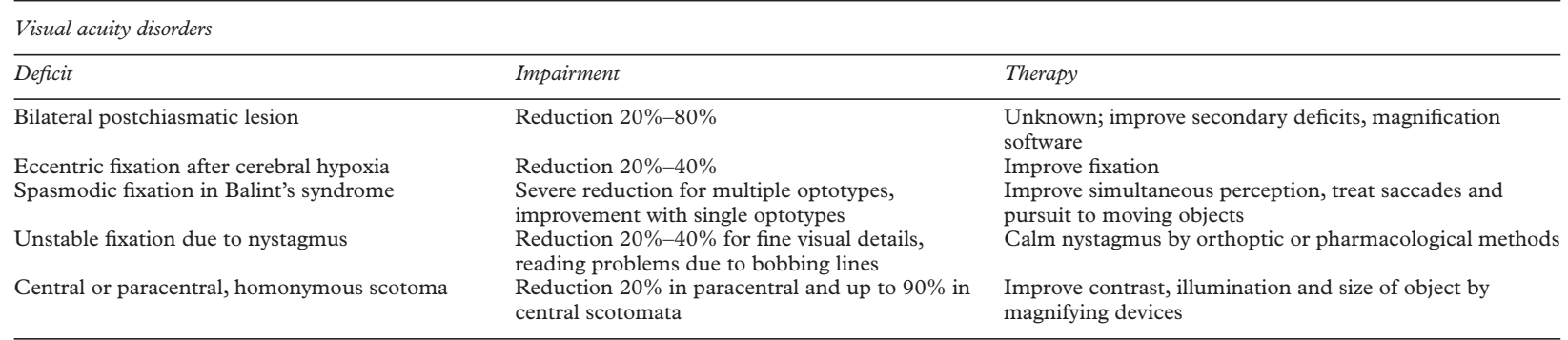

paired adaptation may impair static visual acuity. Eccentric fixation occurs in patients with cerebral hypoxia and may reduce acuity by up to $30 \%$ or more. Acuity recovers in parallel to the fixation disorder. Patients with Balint's syndrome may show a fixation disorder characterised either by exaggerated fixation durations (spasmodic fixation ${ }^{91-94}$ ) and an inability to shift their gaze voluntarily to a new location. This may be mistaken for a considerable acuity loss when tested with standard optotypes. Visual acuity for moving patterns (tested with a rotating drum) may be better preserved in these patients.

Optical aids and magnification software serve to increase image size. Screen reading machines allow the continuous magnification of printed text, books, newspapers, and pictures. Contrast, foreground/background (black/ white or coloured) and luminance can be adapted, which is important for reading. ${ }^{95}$ This technique enables patients with chronic low visual acuity (below 0.40) to read a newspaper, a book, or a letter, thereby participating in "visual" life. Contrast adaptation is also helpful when reading a text without such machines. Increasing the contrast of the text on a sheet of paper increases the legibility of the text. Grey text on grey paper produces a low contrast, black text on white paper a higher contrast.

Commercial software (for example, Metec, München, Germany) is available, which works as a zoom lens that can be combined with standard word processing or graphics software and is operated by the computer mouse. This is helpful for those patients returning to work but its use has to be practised like any other external aid with patients with brain damage as otherwise it will not be used at home or during work. As only a small part of the screen is magnified the patients require intact spatial orientation and imagery to know where they are currently on the display. This is a critical factor in patients with lesions including the parietal cortex which may impair these prerequisites.

Apart from magnification and contrast, visual acuity can be modulated by the degree of lighting. Under high luminance (>1500 lux) visual acuity may reach $2.0(200 \%$, or $\left.40 / 20^{96}{ }^{97}\right)$. Such lighting conditions have been found beneficial in macula disease, ${ }^{98}$ and may increase acuity in scotopic adaptation disorder (see below). However, this has to be established in each patient, as glare and blinding may cancel this effect when photopic adaptation is disturbed as well (see below). Inadequate (too dark or too bright) lighting reduces reading duration and accuracy, increases eye strain, and leads to fatigue in near work..$^{99}$ Because reading and PC work are required in most vocational rehabilitation programmes for patients with brain damage the establishing of comfortable and optimal lighting and the elimination of disturbing factors are important.

Printed text may appear as striped patterns which may evoke eye strain and headache (visual discomfort) in healthy ${ }^{100}$ and visually impaired subjects (unpublished results). Covering the neighbouring lines above and below the currently read line with a mask ${ }^{100}$ may significantly reduce discomfort and glare to improve reading duration, accuracy, and comfort in patients with brain damage as well.

Treatments to improve dynamic visual acuity have not been published yet. Gur et al reported that the smooth pursuit gain can be improved considerably by training. ${ }^{90}$ As reduced dynamic visual acuity is mostly dependent on impaired pursuit movements ${ }^{30}$ the treatment of pursuit eye movements should lead to improvements in dynamic visual acuity. This prediction has not yet been tested empirically.

\section{CONTRAST SENSITIVITY}

Contrast sensivity training in healthy subjects leads to significant and lasting improvements. ${ }^{101}{ }^{102}$ Such training might be considered as a true restitution training and might be partially effective, as contrast sensitive cells are found in many different visual cortical areas ${ }^{103}$ and might enable cortical reorganisation after a lesion. However, such specific training of contrast sensitivity has not been adopted regularly in patients with brain damage. In one remarkable exception ${ }^{104}$ a woman with severe reductions in spatial and temporal contrast sensitivity as well as in acuity due to multiple sclerosis was described. After systematic training with sinusoidal contrast sensitivity patterns all three indices improved markedly. Although very promising this study lacked a control for spontaneous recovery and did not include baseline or follow up measurements. Nevertheless, contrast sensitivity training may be promising in patients with a contrast sensitivity deficit due to a postchiasmatic lesion and complaining about blurred vision, especially in reading.

FOVEAL PHOTOPIC AND SCOTOPIC ADAPTATION No method for direct restitution is available. However, the subjectively debilitating effects (blinding, dark vision, eye strain) can be alleviated using glasses to reduce glare. In cases of selectively disturbed scotopic adaptation, the 
Treatment of convergent fusional disorders

(1) Anamnesis: asthenopic disorders: eye pressure, rapid fatigue in reading, maximal reading duration before blurred vision occurs; decrease in fusional range after visual activities (reading, PC work)

(2) Type of treatment: improvement of binocular fusion and stereoacuity by displaying dichoptic images of increasing disparity angle, mean: 12 treatment sessions (range: 8-20, duration: $20-50$ minutes)

(3) Outcome and follow up: mean increase of vergence amplitude: $12 \mathrm{~cm} / \mathrm{m}$; stablility at follow up (10 months), improvement achievable in $80 \%$ of the patients

(4) Transfer: increase in reading duration, convergent fusion, stereoacuity, and reduction of asthenopic disorders, improved outcome for vocational rehabilitation

(5) Exclusion criteria: premorbid fusional disorders, diplopia with angle $>15^{\circ}$ between both images

use of dimmers and additional, indirect light sources may be helpful. Light absorbing photochromic filters increase reading speed $(+26 \%)$ and letter contrast sensitivity $(+0.3 \mathrm{log}$ units) and reduce the subjective debilitating effects of blinding in patients with head trauma. ${ }^{39}$ Sloan et $a l^{98}$ described significant improvements in acuity and reading in macula disease with additional bright illumination. Similar effects can be achieved in patients with reduced scotopic adaptation: they reach higher static acuity levels with additional high illumination if their photopic adaptation is intact (G Kerkhoff, unpublished results). Flickering neon lights are often used at work but are extremely unpleasant for patients complaining of blinding. Indirect lighting from daylight bulbs is advisable in these cases. Special light bulbs are used by some patients spontaneously to adapt the lighting conditions at home to their subjective light preference. Sunglasses are suitable outside for patients complaining of blinding but varilux glasses (continuously self adapting glasses) are not recommended as they need too long to adapt to a mesopic background illumination when previously exposed to bright light. Cummings et $a l^{\beta 8}$ described a subjective improvement in a patient with blinding ("central dazzle" according to them) after a right thalamic lesion, after medication with amitriptyline hydrochloride and perphenazine. Unfortunately, later removal of the medication reinstated the feeling of "blinding". Obviously, as the neural mechanisms of the adaptation disorder are poorly understood neither restorative nor compensatory treatments are available; optic prostheses are partially effective in reducing disability (reading, glare, acuity).

FUSION AND STEREOPSIS

Despite the considerable improvements achieved through repetitive training in stereovision ${ }^{105}$ fusion and stereopsis are rarely evaluated or trained in neurorehabilitation. Poor spontaneous recovery of the disorder has been described. ${ }^{52}$ Convergent fusion may be effectively improved with orthoptic devices. ${ }^{106}$ Fusional amplitude is trained with dichoptic methods and improves in the course of 8-12 treatment sessions, with parallel improvements in reading duration, stereopsis, and a relief from asthenopic symptoms (table 3). This treatment is highly effective, low cost, easy to implement, improves reading, and reduces asthenopic deficits. Because the deficient fusional process is directly stimulated during treatment it may be considered as a true restorative training. Concerning the mechanisms that guide these considerable improve- ments nothing is known. As many cortical and subcortical visual areas receive binocular input lesions to one visual cortical area might cause only a transient deficit of sensory fusion. Subsequent training of vergence eye movements and sensory fusion-as described in table 3-might then be possible by surviving cortical visual areas which are also devoted to stereoscopic processing. This multiplicity of cortical areas with stereoscopic properties might be the key to the favourable treatment outcome found in fusional and stereoscopic training.

HOMONYMOUS SCOTOMATA: RESTORATIVE APPROACHES

Due to the relatively fixed visual topography in the striate cortex the limits for field recovery through restitution should be relatively firm, as only area 17 contains the relevant visual field representation. As this area resides rather "low" in the visual processing hierarchy cortical plasticity should be limited after a striate cortex lesion. ${ }^{23}$ Restoration of blind visual field regions has been studied repeatedly (extensive overview ${ }^{5}$ ). Despite many long lasting attempts treatment related enlargements of a scotoma $>5^{\circ}$ are rare, occurring in $20 \%-30 \%$ of the patients. Factors predictive of field recovery are incomplete lesions, ${ }^{56}$ a shallow gradient in the profile of light sensitivity in perimetry and amblyopic transition zones, residual metabolism in the lesioned striate cortex, ${ }^{107} 108$ or activations on functional (f) MRI ${ }^{109}$ Patients with such features might be subjected to a functional magnetic reasonance activation study (fMRI) to evaluate if and what type of visual stimulation in the scotoma activates the lesioned visual cortex. ${ }^{109}$ Sabel et al have suggested that $10 \%$ of a lesioned cortical structure may suffice to allow $90 \%$ of the normal functions of this system to work. ${ }^{110}$ If this holds true for the highly topographic visual field representation in cortical area 17 remains to be seen, however. Functional fMRI might assist in selecting patients with such residual structures and determine the most effective site and type of visual stimulation.

Different behavioural procedures have been used in visual field training (table 4). Saccadic localisation and subsequent identification of the presented stimulus (its luminance, form, colour, and motion) is an effective technique. ${ }^{56}$ Identification of various qualities of a stimulus presented in the scotoma without performing a saccade is another useful technique. ${ }^{11}$ The allocation of visual attention (with or without a saccade) towards the stimulated region seems to be a crucial prerequisite for return of vision. 
Table 4 Summary of restorative (visual field training) and compensatory approaches (hemianopic reading and visual exploration training) in patients with postchiasmatic scotomata

Visual field training:

(1) Anamnesis: visual perimetry, tachistoscopic tests: identification of amblyopic transition zones which are most likely candidates for field recovery;

(2) Type of treatment: improvement of saccdic localisation at field border or in amblyopic transition zone; discourage head movements to target; recognition of colour, form, orientation or luminance of the target; amount of treatment sessions: $30-500$ sessions (hours)

(3) Transfer: improvement in reading and subjective awareness of visual problems

(4) Outcome and follow up: mean field increase: $5^{\circ}-10^{\circ}$; stability at follow up; $70 \%$ of patients have a field recovery $<5^{\circ}$

Hemianopic reading training:

(1) Anamnesis: change of line, types of errors (omissions, substitutions, problems with long words or numbers), maximum reading duration, asthenopic disorders (eye strain)

(2) Type of treatment: improvement of oculomotor reading strategies ("reading mechanics") substituting the lost parafoveal visual field; tachistoscopic reading of single words, moving window technique, floating words, search for words in a text, scanning reading technique, training of numbers with embedded zeros: variation of physical and linguistic parameters: word length and frequency, position on screen (left, centre, right), number of words, presentation time, complexity of text, variation of instruction (read $v$ scan text)

(3) Transfer: reading of newspaper, book, own manuscripts; text editing on a PC, increase of maximal reading duration

(4) Outcome and follow up: increase in reading speed; $500 \%$ reduction in reading errors; partial field recovery $\left(\right.$ mean $\left.5^{\circ}\right)$ in $1 / 3$ of patients

Visual exploration training:

(1) Anamnesis: limited overview, bumping into persons and obstacles, defective orientation in visual space, ie crowded situations, traffic

(2) Type of treatment: increasing amplitude of saccadic eye movements towards scotoma: variation of size, increase of velocity of saccade, reduction of saccadic reaction time, reduction of head movements; systematic, spatially organised visual search on wide-field displays: organized search strategy (horizontal or vertical); start search in blind field; visual displays requiring serial and parallel search; possibly combination with other stimulation devices (optokinetic stimulation))

(3) Transfer: orientation in clinic, own urban district, new environments, management of visual activities of daily living: find objects on table or in room, find therapist's room, find objects in supermarket, cross street, use public traffic, find way home

(4) Outcome and follow up: reduction of omissions and search time; partial field recovery (mean: $5^{\circ}-7^{\circ}$ ) in $34 \%$ of patients

READING TRAINING IN VISUAL FIELD DISORDERS Because field restitution is definitely limited in its amount $\left(<6^{\circ}\right)$ few patients will regain normal reading from a visual field enlargement $\left(<10 \%\right.$ of patients with visual field disorders $\left.{ }^{5}\right)$. Instead, compensatory treatment approaches try to improve the eye movements necessary for reading to compensate for the lost field region. ${ }^{57112}$ After an anamnesis of the reading problems and habits treatment starts with the reading of short, high frequency words (table 4). The reading of numbers is trained, which poses a specific problem for all patients with hemianopic alexia as numbers do not permit a semantic control as words normally do. Transfer is established by reading books, their own manuscripts, and doing PC work with text editing, with the final aim to automatise the techniques used and increase reading duration. Using this technique we found significant increases in reading speed and accuracy within 15-25 treatment sessions. ${ }^{112}$ In $34 \%$ of the patients treated in this way a small but significant visual field recovery occurred (mean $5.4^{\circ}$, range $1^{\circ}-20^{\circ 112}$ ). This field recovery is most likely due to the repetitive visual stimulation during reading at the field border, especially in patients with a shallow gradient of light sensitivity along the field border (a broad amblyopic transition zone). Similar results have been found in a recent study, ${ }^{57}$ but without visual field improvements.

SACCADIC AND VISUAL EXPLORATION TRAINING IN VISUAL FIELD DISORDERS

Some $70 \%$ of patients with homonymous visual field disorders show a spatially disorganised visual search strategy. This can be markedly improved by a systematic training of saccadic eye movements and visual search strategies on wide field visual displays (table 4). In a first treatment step the amplitude of saccades towards the scotoma is increased followed by a systematisation of visual search on different displays including pop-out displays and tasks requiring parallel as well as serial visual search. Finally, the transfer of such strategies is trained later in more natural situations - for instance, on a table, in a supermarket, or in traffic. ${ }^{58}$ With these techniques we found significant improvements in visual search that transferred to visual activities of daily living and were subjectively experienced by the patients. ${ }^{58}$ One third of the patients showed a partial field recovery $\left(+12^{\circ}\right.$ on average); this probably resulted from the implemented saccadic eye movement training which leads to partial field restoration. ${ }^{565}$ Positive treatment factors are pure occipital brain lesions without parietal or thalamic involvement and a good awareness for the scotoma and its consequences for daily life. Patients with unawareness due to neglect require more treatment sessions and have a less favourable outcome. ${ }^{113}$ Negative factors are additional visual (peripheral) or oculomotor (nystagmus, pareses) deficits and diffuse disseminated lesions (G Kerkhoff, unpublished results). Head movements during the eye movement training delay progress. ${ }^{113}$ When reflecting about the basic mechanisms of these compensatory treatments for patients with visual field disorders it is most likely a combination of partial, although very limited, field restitution, spatially more organised and rapid eye scanning movements in both hemifields, increased awareness of the visual deficit and its consequences, and the frequent visuomotor practice of the strategies to ensure transfer and automatisation in daily life.

PRISMS

Occasionally, optic devices have been evaluated for the improvement of reading and visual exploration in patients with visual field disorders. Among these are hemianopic spectacles and glass or Fresnel (press on) prisms. Unfortunately, these techniques have not been studied systematically. They were, however, found to be useful in some individual cases. ${ }^{3114}$ Traditionally, prisms are used to substitute for a visual field defect by deviating the patient's gaze towards the defective side to enlarge his functional visual field. ${ }^{3}$ However, a recent 
study suggests that the shift towards the healthy side for a limited time period may be more effective to promote a reorienting of the patient towards the impaired hemifield after later removal of the prisms. ${ }^{115}$ After prism exposure for some days their patients with left sided, visual neglect (five of seven patients had also left sided visual field disorders) showed a compensatory shift in the opposite (left) direction. This led to a significant, albeit transient (2 hours) improvement in neglect related deficits. Hence, the readaptation to a previous prism exposure may be an effective rehabilitation technique to promote cortical reorganisation processes which might apply to patients with visual field disorders without neglect as well.

\section{VISUOSPATIAL PERCEPTION}

Patients with large, right hemispheric lesions show the poorest outcome in neurorehabilitation. ${ }^{116}$ Contralesional neglect, spatial disorders, and unawareness probably contribute to this. Treatment approaches for visual-spatial disorders in these patients can be grouped into two categories: visuoperceptual versus visuomotor treatments. The first try to improve spatial perception by adding facilitating reference cues during therapy, modulating task difficulty by varying the size or orientation difference between the stimuli. Repetitive training with contingent feedback may indeed be very effective to reduce a perceptual deficit. In a recent study a normalisation of visual orientation discrimination was achieved after only 11 treatment sessions. ${ }^{117}$ Transfer to spatially related but untrained tasks was found as well (clock reading, horizontal writing, visuoconstructive performance ${ }^{117}$ ).

By contrast, visuomotor treatments try to improve spatial deficits implicitly by requiring actions towards a particular object or a position in space (assembling pieces to complete a figure, drawing, or pointing to a location ${ }^{118}$ ). Such approaches usually improve visuoperceptual, visuomotor, and planning abilities as acting in space requires preplanning by the patient. Both types of treatment approaches show a significant transfer to activities of daily living (dressing, eating, transfers from bed to wheelchair), clock reading, or spatial orientation during writing. A specific visuospatial add on treatment leads to additional improvements in patients with lesions in the right hemisphere. ${ }^{117}$ As severe visuospatial deficits most often result from parietal lesions, neuroplasticity studies would predict that recovery from such deficits should be higher than after a lesion to a "lower" visual area. It is in accord with this postulate that recovery of visual orientation discrimination in the above study was nearly complete so that most patients reached a nearly normal level. ${ }^{117}$ This encouraging result might indicate that other spatialperceptual deficits resulting from parietal damage might be improved by a similar feedback based training procedure.
Future directions in neurovisual rehabilitation

ENLARGING THE USEFUL FIELD OF VIEW

Standard acuity and perimetry tests underestimate the degree of difficulties experienced by healthy, but aged adults. ${ }^{119}$ Patients with visual field disorders show similar problems in daily activities requiring the use of peripheral vision in the contralesional but also in the ipsilesional hemifield (for example, for detecting vehicles or persons to avoid collisions or falls). Hence, visual field size obtained with perimetric method testing for light detection overestimates the functional capacities of the subject. A more realistic picture of processing capacities in the visual field may be achieved by studying the "useful field of view". The useful field of view is characterised as the visual area in which information can be acquired within one eye fixation. One major difference between standard acuity or perimetry tests and the useful field of view approach is that in the first only one target, often suprathreshold, has to be detected from a homogenous Ganzfeld, whereas in the second a central stimulus is presented, and a peripheral localisation task has to be performed in a cluttered visual background with numerous distractors. This second scenario much more resembles visual scenes in daily life where often many stimuli are to be processed or ignored, partly in parallel. Rizzo ${ }^{61}$ studied the useful field of view in patients with unilateral posterior cerebral artery infarctions causing contralateral hemianopia. His patients did not only show a reduction of the UFOV in the blind field-which is expected due to the scotoma - but also in the ipsilesional hemifield, though to a lesser degree. Such a constricted useful field of view will lead to omissions of targets in peripheral vision in both the blind and the "intact" hemifield. In accordance with this observation we found in an earlier study with hemianopic patients, impairments in visual search not only in the blind field but also to a lesser degree in the ipsilesional field. ${ }^{58}$ These impairments were partially reversible after intensive treatment. ${ }^{58}$ Hence, the useful field of view was enlarged by this training. In a somewhat different approach ${ }^{120}$ a significant and stable expansion of the useful field of view in healthy, aged adults without visual field disorders was achieved after systematic training. This treatment could easily be implemented in visual rehabilitation procedures for patients with cerebral lesions.

\section{GAZE DEPENDENT MODULATION OF VISUAL}

DEFICITS

Numerous animal studies show that the neuronal response of cells in the visual, motor, and parietal cortex is modulated either by orbital eye position ${ }^{121-123}$ or head position. ${ }^{124}$ Because this effect has been found in many cortical areas (including visual, motor, and parietal cortex) it seems to reflect a general principle of the nervous system. Few clinical studies have sought to investigate this modulatory effect as a source of residual, although yet transient, visual capacities in neurorehabilitation. Head turning towards a left sided scotoma leads to a relative 
gaze shift to the right side when fixating straight ahead. This technique transiently normalised the left upper quadrantanopia in two patients. ${ }^{525}$ Although the precise mechanisms of this gaze modulated effect are not clear at present (attentional right hemisphere activation or neck proprioceptive stimulation) ipsilesional (rightward) gaze led to a significant $(19.2 \%)$ increase in cerebral blood flow in a similar patient, as measured with SPECT, in Brodman areas 1,2,3,7, 21, 22, 39, and 40 of the damaged hemisphere (motor and parietal cortices). ${ }^{126}$ In a similar patient with right upper quadrantanopia ${ }^{5}$ head orientation to the right (with gaze to the left) reduced the scotoma in the right upper quadrant by about $20^{\circ}$ without changes in the ipsilesional field border.

Interestingly, such facilitatory effects of gaze orientation are not limited to visual field disorders. They have been shown in line bisection and reading of patients with visual neglect. ${ }^{127}$ Head orientation towards the neglected hemispace, which leads to a rightward gaze shift when fixating straight ahead transiently normalised these deficits, ${ }^{127}$ and neck muscle vibration has recently been shown to reduce neglect permanently. ${ }^{128}$ In summary, gaze modulation might be an interesting technique to disclose and elicit residual visual capacities. How these can be coined into permanent visual improvements remains to be established.

ACTIVATION OF IMPAIRED VISUAL FUNCTIONS THROUGH VISUAL MOTION STIMULI

Several cortical and subcortical visual areas are involved in the processing of visual motion. ${ }^{103}$ Surprisingly few patients with focal brain lesions show persistent deficits in global motion perception (apparently $13 \%{ }^{129}$ ). Likewise, monkeys with focal lesions of the superior temporal sulcus show a quick recovery of smooth pursuit eye movements within a few weeks. ${ }^{130}$ One reason for this robustness of visual motion perception may reside in the multiplicity of cerebral areas involved in visual motion processing. Consequently, a focal lesion does not completely abolish it. This preserved motion perception might be used to stimulate or modulate other visual abilities or deficits. Large field visual displays rotating around the fixation point modulate the apparent judgment of gravity in normal subjects. ${ }^{131}$ Similarly, optokinetic stimulation with large field displays drifting leftwards modulates the subjective midline in left visual neglect, ${ }^{132}$ and reduces visual size and space distortions in neglect. ${ }^{133134}$ One attractive feature of this technique lies in the fact that it has no adverse effects and does not require conscious awareness.

In several experiments we evaluated the potential effects of various stimulations using visual motion cues, which were studied in three different visual disorders: visual dyslexia due to hemianopia and neglect ${ }^{135}$ (fig $4 \mathrm{~A}$ ), visual size distortion in left sided neglect ${ }^{133}{ }^{134}$ (fig $4 \mathrm{~B}$ ), and visuospatial deficits (fig $4 \mathrm{C}$ ). With the appropriate type of stimulation a nearly complete normalisation of all three deficits was achieved. Although these findings show a transient modulation of visual deficits repetitive stimulation could eventually lead to stable improvements. One basic mechanism of the modulatory effects of global visual motion probably resides in the fact that many cortical visual areas respond to motion stimuli and some respond even when a blind field is stimulated with optokinetics. ${ }^{136}$ Again, the multiplicity of cortical "motion" areas and especially those still responding after being deafferented from their direct input from the striate cortex (as in the case of hemianopia) might be a key to a better functional recovery.

IMPROVING COGNITIVE AWARENESS (METAVISION) When we look directly into the sun we feel blinded and look away, or use sunglasses. This immediate adaptation requires some knowledge about the basic mechanisms of glare and the appropriate remedy. However, in most instances our visual and oculomotor systems do not alert us about serious deficits or limitations. This is the reason why more than $60 \%$ of hemianopic patients have only limited or no correct awareness of their field defect immediately after their disease. ${ }^{137}$ Awareness must be improved during rehabilitation to maximise outcome and enable reintegration of the patient into the community. ${ }^{138}$ Awareness can be assessed in the acute stage by a simple questionnaire ${ }^{137}$; in later rehabilitation stages more detailed questionnaires are useful. ${ }^{138}$ Frequent information about the cause of a visual disorder, the direct demonstration of the deficit (for example, presenting the visual field chart repeatedly), and the consequences (for example, bumping into a door frame), as well as relative improvements during training (for example, larger visual search field after therapy) may be mportant steps to promote "metavision" on the patient side (named in analogy with "metamemory"4). Furthermore, knowledge about the disorder and the techniques to cope with it is necessary to motivate the patient for treatment and improve the transfer to daily life. In this sense, patients who know more about their impairments and possible coping strategies are likely to require less treatment, will have less complications, and have a better outcome in daily life. Among such approaches the development of support groups and health education programmes might be the most promising.

SUPPORT GROUPS, HEALTH EDUCATION, AND PATIENT INFORMATION

Health education programmes ${ }^{139}$ and support groups $^{140}$ for elderly, visually impaired people with eye disease have been successfully implemented, but similar programmes in neurovisual rehabilitation are currently unknown. In such approaches it has often been found that elderly visually impaired people do not have sufficient knowledge about their disease (for example, diabetic retinopathy) and the implications of it for activities of daily living. As a consequence these patients often do not have a realistic perception of their disease ${ }^{139}$ and the resulting disabilities as well as relatively preserved capacities which 
JEDER MENSCH, DER IHN EINMAL ODER ZWEIMAL GEHÖRT HAT, WIRD IHN NIE VERGESSEN: DEN

SCHARFEN, ALLES DURCHDRINGENDEN WARNPFIFF DER MURMELTIERE. WENN SICH EIN ADLER DEN

MUNTEREN FLINKEN ALPENBEWOHNERN NÄHERT, DANN PFEIFEN SIE LOS, SO SCHRILL WIE MANCHE VÖGEL. SIE WARNEN SICH DAMIT GEGENSEITIG; UND ALLE

FREMDEN UND FAMILIENMITGLIEDER SIND FLUGS IN IHREM BAU VERSCHWUNDEN.

IM HOHEN NORDEN, IM EISMEER IST ALLES STILL

SCHWERE EISSCHOLLEN TREIBEN RUHIG IM MEER, UND SCHNEEBERGE GLITZERN IN DER

SONNE. PLÖTZLICH DURCHDRINGT

EIN GEWALTIGES

SCHNAUBEN UND PRUSTEN DIE STILLE. DER

WUCHTIGE KOPF EINES RIESIGEN EISBÄREN

TAUCHT AUS DEN KALTEN FLUTEN AUF

EINE WOLKE VERBRAUCHTER ATEMLUFT STRÖMT AUS SEINEN NASENLÖCHERN

No motion

Left

motion
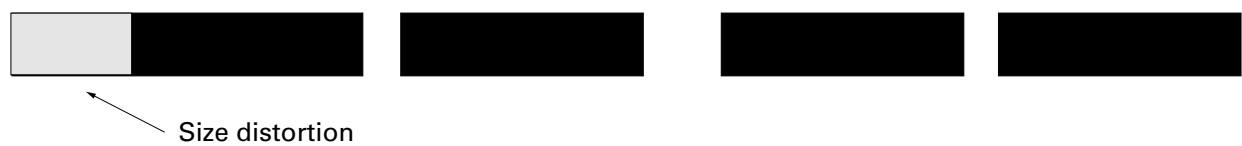

C
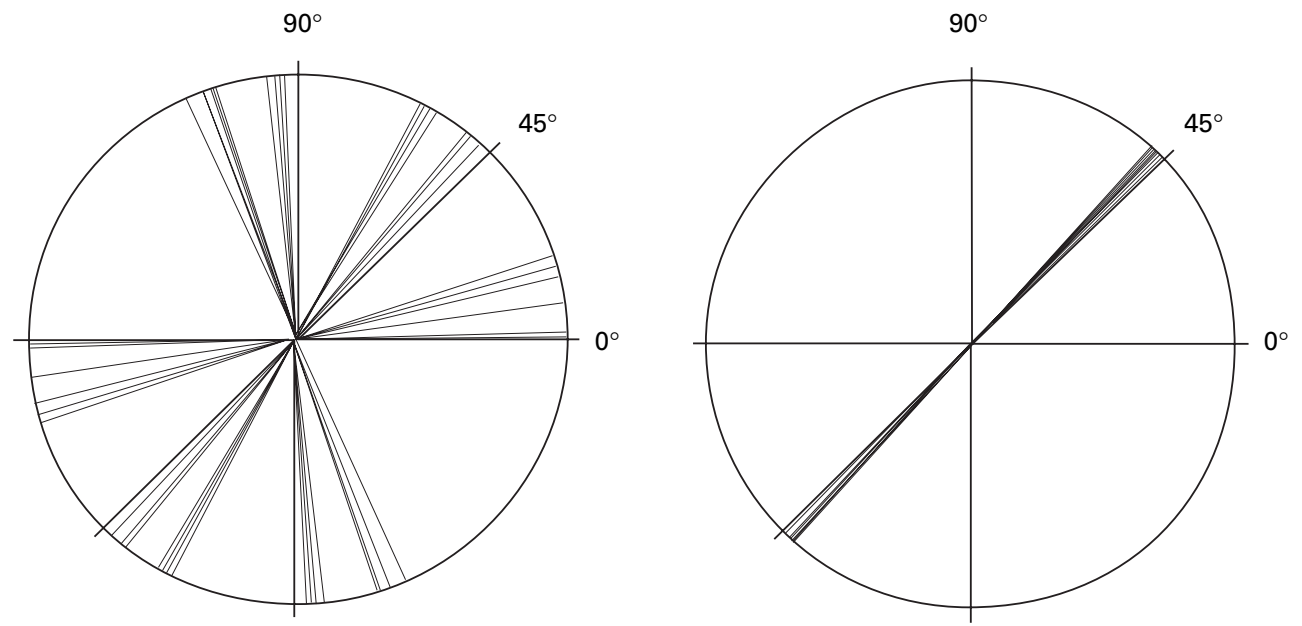

Figure 4 Examples of motion dependent modulation of visual deficits. (A) Reading performance of a 56 year old woman with a right temporoparietal lesion 5 months after onset. She had left homonymous hemianopia (field sparing $2^{\circ}$ ), and left sided visual neglect. She showed 20 left sided omissions (34\%, errors in bold) in an indented reading test presented on a PC monitor (no motion). When the text was surrounded by a frame on which 150 squares drifted linearly towards the left side with $7.5^{\circ} \mathrm{s}^{-1}$ (left motion), her reading of a similar text was significantly improved (3 omissions, 6\%). (B) Visual horizontal size judgment in a 45 year old patient with left neglect and left sided homonymous hemianopia (field sparing $3^{\circ}$ ). In the baseline condition without moving background (no motion) the subject misjudged the horizontal size of the bar by about 50\% (size distortion error ${ }^{134}$ ). Adding background stimuli (150 squares) moving coherently towards the left side with $7.5^{\circ} \mathrm{s}^{-1}$ (left motion) completely normalised the size error. (C) Disturbed spatial perception of the subjective visual vertical $\left(90^{\circ}\right)$, visual horizontal $\left(0^{\circ}\right)$ and a right oblique orientation $\left(45^{\circ}\right)$ in a patient with a right parietal lesion 3 months after onset. Note the significant counterclockwise rotation of all three orientations in the baseline condition (no motion). Presenting background motion (150 small, circular dots) drifting coherently clockwise around the line of sight normalised this spatial tilt in all three tasks (clockwise motion).

might help the patient to remain functionally independent as long as possible. Furthermore, it was found that the patients' relatives were often inadequately informed about the disease, too.
After weekly meetings within a small (4-6 people) support group of patients with eye disease typically occurring in old age $\mathrm{e}^{139} 140$ it was found that functional independence could be 
increased, along with improved self satisfaction. The main purpose of support groups and health education programmes in patients with cerebral visual disorders hence could be to share concrete knowledge about visual impairments, implement or refresh practical compensation strategies, and increase the patient's awareness and functional independence. As many cerebral visual disorders are hardly "visible" for the relatives or other persons (by contrast with a motor or speech deficit), another purpose of such education programmes should be to inform these people about the basis and the implications of cerebral visual disorders.

\section{Summary and conclusions}

Neurovisual rehabilitation is a newly developing field combining findings from neuropsychology, neuroplasticity, neuroophthalmology, and neurophysiology to develop new or refine existing treatment methods for patients with acquired central visual disorders. At present, full restoration of function is achieved only in a few patients, which either reflects the relatively firm limits of cortical plasticity and functional recovery after brain damage, or our lack of knowledge limiting the design of more effective treatment methods. Nevertheless, compensatory improvements in functionally relevant visual abilities for daily living such as visual search and spatial orientation, reading, and fusion can be achieved in most visually impaired patients, indicating some potential for recovery and relearning of visuomotor strategies. These available treatments significantly reduce the patient's disability and handicap and improve subjective quality of life. Most of the required treatments are low cost, easy to implement, and their effectiveness has been studied. Future rehabilitation studies could seek to uncover residual visual capacities, study novel stimulation procedures, and improve awareness to maximise outcome.

I am grateful to Mrs Antje Waddington, Bielefeld, Germany, for her assistance with language, and three anonymous reviewers for helpful comments.

1 Zihl J. Cerebral disturbances of elementary visual functions. In: Brown JW, ed. Neuropsychology of visiual perception. New York: Lawrence Erlbaum Associates, 1988.

2 Fowler MS, Wade DT, Richardson AJ, et al. Squints and diplopia seen after brain damage. 7 Neurol 1996;243:86-90.

3 Rossi PW, Kheyfets S, Reding MJ. Fresnel prisms improve visual perception in stroke patients with homonymous hemianopia or unilateral visual neglect. Neurology 1990;40: 1597-9.

4 Gianutsos R. Vision rehabilitation following acquired brain injury. In: Gentile M, ed. Functional visual behavior. A therapists guide to evaluation and treatment options. Bethesda, MD: American Occupational Therapist Organisation, 1997:267Americ

5 Kerkhoff G. Restorative and compensatory therapy approaches in cerebral blindness. A review. Restorative Neurology and Neuroscience 1999;13:255-71.

6 Reding MJ, Potes E. Rehabilitaton outcome following initial unilateral hemispheric stroke: life table analysis approach Stroke 1990;19:1354-8.

7 Savir H, Michelson I, David C, et al. Homonymous hemianopsia and rehabilitation in 15 cases of CCI. Scand $\mathcal{f}$ Rehabi Med 1977;9:151-3.

8 Bruell JH, Peszczynski M. Perception of verticality in hemiplegic patients in relation to rehabilitation. Clin Ophthal 1958;12:124-30.

9 Denes G, Semenza C, Stoppa E, et al. Unilateral spatial neglect and recovery from hemiplegia. A follow up study. Brain 1982;105:543-52.

10 Diller L, Weinberg J. Evidence for accident-prone behavior in hemiplegic patients. Arch Phys Med Rehabil 1970;51: 358-63.
11 Baum B, Hall KM. Relationship between constructional praxis and dressing in the head-injured adult. Am $\mathcal{F}$ Occup Ther 1981;35:438-42.

12 Webster JS, Roades LA, Morrill B, et al. Rightward orienting bias, wheelchair maneuvering, and fall risk. Arch Phys Med Rehabil 1995;76:924-8.

13 Williams N. Correlation between copying ability and dressing activities in hemiplegia. Am f Phys Med 1967;46:133240 .

14 Kaplan J, Hier DB. Visuospatial deficits after right hemisphere stroke. Am f Occup Ther 1982;36:314-21.

15 Warren M. Relationship of constructional apraxia and body scheme disorders to dressing performance in adult CVA. Am f Occup Ther 1981;35:431-7.

16 Walker MF, Lincoln NB. Factors influencing dressing performance after stroke. $\mathcal{f}$ Neurol Neurosurg Psychiatry 991;54:699-701.

17 Paolucci S, Traballesi M, Giallloretti LE, et al. Changes in functional outcome in inpatient stroke rehabilitation resulting from new health policy regulations in Italy. European Fournal of Neurology 1998;5:17-22.

18 Straube A, Kennard C. Ocular motor disorders. In: Brandt T, et al, Neurological disorders. Course and treatment. San Diego: Academic Press, 1996:101-11.

19 Robertson IH. Cognitive rehabilitation: attention and neglect. Trends in Cognitive Sciences 1999;3:385-93.

20 McMillan TM, Robertson IH, Wilson BA. Neurogenesis after brain injury: implications for neurorehabilitation. after brain injury: implications for neurorehabilition 1999;9:129-133.
Neuropsychological Rehabilitation

21 Kempermann G, Brandon EP, Gage FH. Environmental stimulation of $129 /$ Svj mice causes increased cell proliferation and neurogenesis in the adult dentate gyrus. Curr Biol 1998;8:939-42.

22 Buonomano DV, Merzenich MM. Cortical plasticity: from synapses to maps. Ann Rev Neurosci 1998;21:149-86.

$23 \mathrm{Kaas} \mathrm{JH}$. The reorganization of sensory and motor maps in adult mammals. In: Gazzaniga MS, ed. The cognitive neurosciences. Cambridge, Massachusetts: MIT Press, 1995:5172 .

24 Frisén L. The neurology of visual acuity. Brain 1980;103: 639-70.

25 Walsh FB, Lindenberg R. Hypoxia in infants and children: a clinical pathological study concerning the primary visual pathways. Bulletin of the Hopkins Hospitals 1961;108:10045.

26 Hoyt WF, Walsh FB. Cortical blindness with partial recovery following acute cerebral anoxia from cardic arrest. Arch Ophthalmol 1958;60:1060-9.

27 Aldrich MS, Alessi AG, Beck RW, et al. Cortical blindness: etiology, diagnosis, and prognosis. Ann Neurol 1987;21: 149-58.

28 Savino PJ, Paris M, Schatz NJ, et al. Optic tract syndrome. Arch Ophthalmol 1978;96:656-63.

29 Newman SA, Miller NR. Optic tract syndrome. Neuroophthalmological considerations. Arch Ophthalmol 1983; 101:1241-50

30 Haarmeier T, Thier P. Impaired analysis of moving objects due to deficient smooth pursuit eye movements. Brain 1999;122:1495-505.

31 Kosnik W, Winslow L, Kline D, et al. Visual changes in daily life throughout adulthood. F Gerontol 1988;43:P63-7.

32 Hess RF, Zihl J, Pointer JS, et al. The contrast sensitivity deficit in cases with cerebral lesions. Clinical Vision Sciences 1990;5:203-15.

33 Owsley C, Sloane ME. Contrast sensitivity, acuity, and the perception of "real-world" targets. $\mathrm{Br} f$ Ophthalmol 1987;71:791-6.

34 Bodis-Wollner I. Vulnerability of spatial frequency channels in cerebral lesions. Nature 1976;261:309-11.

35 Bulens C, Meerwaldt JD, Van der Wildt GJ, et al. Spatial contrast sensitivity in unilateral cerebral ischaemic lesions involving the posterior visual pathway. Brain 1989;112: 507-20.

36 Ullrich N. Adaptionsstörungen bei Sehhirnverletzten. Deutsche Zeitschrift für Nervenheilkunde 1943;155:1-31.

37 Zihl J, Kerkhoff G. Foveal photopic and scotopic adaptation in patients with brain damage. Clinical Vision Sciences 1990; 2:185-95.

38 Cummings JL, Gittinger JW. Central dazzle. A thalamic syndrome? Arch Neurol 1981;38:372-4.

39 Jackowski MM, Sturr JF, Taub HA, et al. Photophobia in patients with traumatic brain injury: uses of light-filtering patients with traumatic brain injury: uses of light-filtering Neurorehabilitation 1996;6:193-201.

40 Waddell PA, Gronwall DMA. Sensitivity to light and sound following minor head injury. Acta Neurol Scand 1984;69: 270-6.

41 Rizzo M. Astereopsis. In: Boller F, Grafman J, eds. Handbook of neuropsychology. Amsterdam: Elsevier, 1989: 415-27.

42 Ptito A, Zatorre RJ, Larson WL, et al. Stereopsis after unilateral anterior temporal lobectomy. Brain 1991;114: 1323-33.

43 Ptito A, Zatorre RJ. Impaired stereoscopic detection thresholds after left or right temporal lobectomy. Neuropsychologia 1988;26:547-54

44 Gulyás B, Roland PE. Binocular disparity discrimination in human cerebral cortex: functional anatomy by positron
emission tomography. Proc Nat Acad Sci USA 1994;91: emission $1239-43$.

45 Sakata H, Taira M, Murata A, et al. The parietal association cortex in depth perception and visual control of hand action. Trends Neurosci 1997;20:350-7. 
46 Stögerer E, Kerkhoff G. Behandlung von Störungen des beidäugigen Sehens (Fusion, Stereosehen) nach Hirnschädibeidäugigen Sehens (Fusion, Stereos
gung. Dortmund: Borgmann, 1995.

47 Zee DS, Levi L. Neurological aspects of vergence eye movements. Rev Neurolog 1989;145:613-20.

48 Mays LE. Neural control of vergence eye movements: convergence and divergence neurons in midbrain. $f$ Neurophysiol 1984;51:1091-108.

49 Mays LE, Gamlin PDR. Neuronal circuitry controlling the near response. Curr Opin Neurobiol 1995;5:763-68.

50 Jaensch PA. Fusionsstörungen. Horror fusionis und Konvergenzspasmen. Klinische Monatsblätter für Augenheilkunde vergenzspasmen. Kür Augenärztliche Fortbildung 1946;111:142-9.

51 Franceschetti A, Klingler M. 3. Die posttraumatische Encephalopathie. Schweizer Archiv für Neurologie, NeuroEncephalopathie. Schweizer Archiv für Neur
chirurgie und Psychiatrie 1943;50:267-344.

52 Doden W, Bunge H. Fusionsstörungen nach Schädelhirntraumen. Monatsblätter für Augenheilkunde 1965;146:84553.

53 Hart CT. Disturbances of fusion following head injuries. Proceedings of the Royal Society of Medicine 1969;62:704-6.

54 Lambert SR, Hoyt CS, Jan JE, et al. Visual recovery from hypoxic cortical blindness during childhood. Computed tomographic and magnetic resonance imaging predictors. Arch Ophthalmol 1987;105:1371-7.

55 Uzzell BP, Dolinskas CA, Langfitt TW. Visual field defects in relation to head injury severity. Arch Neurol 1988;45: $420-4$

56 Zihl J, von Cramon D. Visual field recovery from scotoma in patients with postgeniculate damage. Brain 1985;108:335-

57 Zihl J. Eye movement patterns in hemianopic dyslexia. Brain 1995;118:891-912.

58 Kerkhoff G, Münßinger U, Meier EK. Neurovisual rehabilitation in cerebral blindness. Arch Neurol 1994;51:474-81.

59 Meienberg O, Zangemeister WH, Rosenberg M, et al. Saccadic eye movement strategies in patients with homonymous hemianopia. Ann Neurol 1981;9:537-44.

$60 \mathrm{Zihl}$ J. Visual scanning behavior in patients with homonymous hemianopia. Neuropsychologia 1995;33:287-303.

61 Rizzo M, Robin DA. Bilateral effects of unilateral visual cortex lesions in human. Brain 1996;119:951-63.

62 Kerkhoff G, Zoelch C. Disorders of visuospatial orientation in the frontal plane in patients with neglect following righ or left parietal lesions. Exp Brain Res 1998;122:108-20.

63 McConkie GW, Rayner K. The span of the effective stimulus during a fixation in reading. Perceptual Psychophysics 1975;17:578-86.

64 Warrington EK, Rabin P. Perceptual matching in patients with cerebral lesions. Neuropsychologia 1970;8:475-87.

65 Cramon Dv, Kerkhoff G. On the cerebral organization of elementary visuo-spatial perception. In: Gulyas B, Ottoson D, Roland P, eds. Functional organisation of the human visual cortex. Oxford: Pergamon, 1993:211-31.

66 De Renzi E. Disorders of space exploration and cognition. Chichester: Wiley, 1982:1-268.

67 Tartaglione A, Cocito L, Bino G, et al. Further evidence for asymmetry of point localisation in normals and unilateral brain damaged patients. Neuropsychologia 1983;21:40712.

68 Hier DB, Mondlock J, Caplan LR. Recovery of behavioral abnormalities after right hemisphere stroke. Neurology 1983;33:345-50.

69 Meerwaldt JD, Van Harskamp F. Spatial disorientation in right-hemisphere infarction. F Neurol Neurosurg Psychiatry 1982;45:586-90

70 Zihl J, Kennard C. Disorders of higher visual functions. In: Brandt T, Caplan L, Dichgans J, et al, eds. Neurological disorders. Course and treatment. San Diego: Academic Press, orders. Course

71 Farah M. Visual agnosia. Cambridge, Massachusetts: MIT Press, 1990:1-184

72 Whiteley AM, Warrington EK. Prosopagnosia: a clinical, psychological, and anatomical study of three patients. $f$ Neurol Neurosurg Psychiatry 1977;40:395-403.

73 Damasio AR, Tranel D, Damasio H. Face agnosia and the neural substrates of memory. Ann Rev Neurosci 1990;13 89-119.

74 Anderson SW, Rizzo M. Recovery and rehabilitation of visual cortical dysfunction. Neurorehabilitation 1995;5:12940 .

75 Benton AL, Hamsher KD, Varney NR, et al. Contributions to neuropsychological assessment. A clinical manual. New York: Oxford University Press, 1983:1-146.

76 Humphreys GW, Riddoch MJ. Visual object processing in normality and pathology: implications for rehabilitation. In: Riddoch MJ, et al. Cognitive neuropsychology and rehabilitation. Howe: Lawrence Erlbaum, 1993:39-76.

77 Rizzo M. "Balint's syndrome" and associated visuospatial disorders. Baillieres Clin Neurol 1993;2:415-37.

78 Rafal R D. Balint syndrome. In: Feinberg TE, Fahrah M, et al, eds. Behavioral neurology and neuropsychology. Boston: McGraw-Hill, 1997:337-356.

79 Mendez MF, Tomsak RL, Remler B. Disorders of the visual system in Alz

80 Perez FM, Tunkel RS, Lachmann EA, et al. Balint's syndrome arising from bilateral posterior cortical atrophy or infarction: rehabilitation strategies and their limitation. Disabil Rehabil 1996;18:300-4.

81 Pierrot-Deseilligny C. Saccade and smooth-pursuit impairment after cerebral hemispheric lesions. Eur Neurol 1994;34:121-34.
82 De Renzi E, Colombo A, Faglioni P, et al. Conjugate gaze paresis in stroke patients with unilateral damage. An unexpected instance of hemispheric asymmetry. Arch Neurol 982;39:482-6

83 Kömpf D, Gmeiner H-J. Gaze palsy and visual hemineglect in acute hemisphere lesions. Neuroophthalmology 1988;9: 49-53.

84 Tijssen CC, Gisbergen JAMv. Conjugate eye deviation after hemispheric stroke. A contralateral saccadic palsy? Neuroophthalmology 1993;13:107-18.

85 Cohn R. Eyeball movements in homonymous hemianopia following simultaneous bitemporal object presentation. Neurology 1972;22:12-14.

86 Waespe W, Wichmann W. Oculomotor disturbances during visual-vestibular interaction in Wallenberg's lateral medullary syndrome. Brain 1990;113:821-46.

87 Morrow MJ, Sharpe JA. Cerebral hemisperic localization of smooth pursuit asymmetry. Neurology 1990;40:284-92.

88 Lekwuwa GU, Barnes GR. Cerebral control of eye movements. I. The relationship between cerebral lesion sites and smooth pursuit deficits. Brain 1996;119:473-90.

89 Heide W, Kurzidim K, Kömpf D. Deficits of smooth pursuit eye movements after frontal and parietal lesions. Brain 1996;119:1951-69.

90 Gur S, Ron S. Training in oculomotor tracking: occupational health aspects. Isr f Med Sci 1992;28:622-8.

91 Allen IM. Exaggeration of fixation of gaze. $N Z$ Med 71962 ; 61:101-7.

92 Tyler HR. Abnormalities of perception with defective eye movements (Balint's syndrome). Cortex 1968;8:154-71

93 Johnston JL, Sharpe JA, Morrow MJ. Spasm of fixation: a quantitative study. F Neurol Sci 1992;107:166-71.

94 Holmes G. Spasm of fixation. Transactions of the Opthalmological Society 1930;50:253-62.

95 Brown B. Reading performance in low vision patients: relation to contrast and contrast sensitivity. American fournal of Optometry and Physiological Optics 1981;58:218-26.

96 Hartmann E, Scheffzyk-Hagl A, Lachenmayr B. Der Einflu $\beta$ von Beleuchtungsstärke, Leuchtdichte, Kontrast und Farbe auf das Sehvermögen von Patienten mit leichter bis hochgradiger Sehbehinderung. Klin Monatsbl Augenheilkd 1980;177:304-18.

97 Richards OW. Effects of luminance and contrast on visual acuity, ages 16-90 years. American fournal of Optometry and Physiological Optics 1977;54:178-84.

98 Sloan LL, Habel A, Feiock K. High illumination as an auxiliary reading aid in diseases of the macula. Am f Ophthalmol 1973;76:745-57.

99 Luckiesh M, Moss FK. Fatigue of convergence induced by reading as a function of illumination intensity. $A m \mathcal{F}$ Ophthalmol 1935;18:319-23.

100 Wilkins AJ, Nimmo-Smith I. On the reduction of eye-strain when reading. Ophthalmic Physiol Opt 1984;4: $53-9$.

101 Mayer MJ. Practice improves adults' sensitivity to diagonals. Vision Res 1983;23:547-50.

102 De Valois KK. Spatial frequency adaptation can enhance contrast sensitivity. Vision Res 1977;17:1057-65.

03 Van Essen DC, De Yoe EA. Concurrent processing in the primate visual cortex. In: Gazzaniga MS, ed. The cognitive neurosciences. Cambridge, Massuchesetts: MIT Press, 1995:383-400.

104 Rentschler I, Baumgartner G, Campbell FW, et al. Analysis and restitution of visual function in a case of cerebral amblyopia. Hum Neurobiol 1982;1:9-16.

105 Fendick M, Westheimer G. Effects of practice and the separation of test targets on foveal and peripheral separation of test targets on foveal

106 Kerkhoff G, Stögerer E. Recovery of fusional convergence after systematic practice. Brain Injury 1994;8:15-22.

107 Bosley TM, Rosenquist AC, Kushner M, et al. Ischemic esions of the occipital cortex and optic radiations: positron emission tomography. Neurology 1985;35:470-84

08 Kiyosawa M, Bosley TM, Kushner M, et al. Middle cerebral artery strokes causing homonymous hemianopia: positron emission tomography. Ann Neurol 1990;28:180-3.

109 Miki A, Nakajima T, Fujita M, et al. Functional magneticresonance-imaging in homonymous hemianopia. $A m f$ Ophthalmol 1996;121:258-66.

110 Sabel BA, Kasten E, Kreutz MR. Recovery of vision after visual system injury as a model of postlesion neuroplasticity. In: Freund HJ, Sabel BA, Witte OW, et al, Brain plasticity. Philadelphia: Lippincott-Raven, 1997:251-76.

111 Kasten E, Sabel BA. Visual field enlargement after computer training in brain-damaged patients with homonymous deficits: an open pilot trial. Restorative Neurology and Neuroscience 1995;8:113-127.

112 Kerkhoff G, Münßinger U, Eberle-Strauss G, et al. Rehabilitation of hemianopic alexia in patients with postgeniculate visual field disorders. Neuropsychol Rehabilitation 1992;2:21-42.

13 Kerkhoff G, Münßinger U, Haaf E, et al. Rehabilitation of homonymous scotomata in patients with postgeniculate damage of the visual system: saccadic compensation training. Restorative Neurology and Neuroscience 1992;4:245-254.

114 Bailey IL. Prismatic treatment for field defect. Optometric Monthly 1978;69:1073-8.

115 Rossetti Y, Rode G, Pisella L, et al. Prism adaptation to a rightward optical deviation rehabilitates left hemispatial neglect. Nature 1998;395:166-9.

116 Ween JE, Alexander MP, D‘Esposito M, et al. Factors predictive of stroke outcome in a rehabilitation setting. Neurology 1996;47:388-92. 
117 Kerkhoff G. Rehabilitation of visuospatial cognition and visual exploration in neglect: a cross-over study. Restorative visual exploration in neglect:

118 Weinberg J, Piasetsky E, Diller L, et al. Treating perceptual organization deficits in non-neglecting RBD stroke patients. F Clin Exp Neuropsychol 1982;4:59-75.

119 Ball K, Owsley C, Beard B. Clinical visual perimetry underestimates peripheral field problems in older adults. Clinical Vision Sciences 1990;5:113-25.

120 Ball K, Beard BL, Roenker DL, et al. Age and visua search: expanding the useful field of view. F Opt Soc Am A 1988;12:2210-19.

121 Andersen RA, Snyder LH, Bradley DC, et al. Multimodal representation of space in the posterior parietal cortex and its use in planning movements. Ann Rev Neurosci 1997;20: 303-30.

122 Galletti C, Battaglini PP, Fattori P. Eye position influence on the parieto-occipital area PO (V6) of the macaque monon the parieto-occipital area PO (V6)
key. Eur $\mathcal{F}$ Neurosci 1995;7:2486-501.

123 Boussaoud D. Primate premotor cortex: modulation of preparatory neuronal activity by gaze angle. $\mathcal{F}$ Neurophysiol preparatory neur

124 Brotchie PR, Andersen RA, Snyder LH, et al. Head position signals used by parietal neurons to encode locations of visual stimuli. Nature 1995;375:232-5.

125 Nadeau SE, Heilman KM. Gaze-dependant hemianopia without hemispatial neglect. Neurology 1991;41:1244-50.

126 Nadeau SE, Crosson B, Schwartz RL, et al. Gaze related enhancement of hemispheric blood flow in a stroke patient. f Neurol Neurosurg Psychiatry 1997;62:538-40.

127 Schindler I, Kerkhoff G. Head and trunk orientation modulate visual neglect. Neuroreport 1997;8:2681-5.

128 Schindler I, Kerkhoff G, Karnath H-O, et al. Neck muscle vibration and visual exploration training: a cross-over study on neglect rehabilitation. Acta Neurobiologiae Experimentalis 1999;56:69.

129 Schenk T, Zihl J. Visual motion perception after brain damage: I. Deficits in global motion perception. Neuropsychologia 1997;35:1289-97.
130 Newsome WT, Wurtz RH, Dürsteler MR, et al. Deficits in visual motion processing following ibotenic acid lesions of the middle temporal visual area of the macaque monkey. $f$ Neurosci 1985;5:825-40.

131 Dichgans J, Held R, Young LR, et al. Moving visual scenes influence the apparent direction of gravity. Science 1972; 178:1217-19.

132 Pizzamiglio L, Frasca R, Guariglia C, et al. Effect of optokinetic stimulation in patients with visual neglect. Cortex 1990;26:535-40.

133 Kerkhoff G, Schindler I, Keller I, et al. Visual background motion reduces size distortions in spatial neglect. Neuroreport 1999;10:319-23.

134 Kerkhoff G. Multiple perceptual distortions and their modulation in leftsided visual neglect. Neuropsychologia 1999;37:1387-405.

35 Kerkhoff G, Kriz G, Keller I, et al. Head direction and optokinetic stimulation modulate space-based but not word-based neglect dyslexia. Neural Plasticity 1999; 126(suppl 1):155-6.

136 Brandt T, Bucher SF, Seelos KC, et al. Bilateral functional MRI activations of the basal ganglia and middle temporal/ medial superior temporal motion-sensitive areas: optokinetic stimulation in homonymous hemianopia. Arch Neurol 1998;55:1126-31.

137 Celesia GG, Brigell M, Vaphiades MS. Hemianopic anosognosia. Neurology 1997;49:88-97.

138 Sherer M, Oden K, Bergloff P, et al. Assessment and treatment of impaired awareness after brain injury: implications for comunity re-integration. Neurorehabilitation 1998;10: 25-37.

139 Dahlin-Ivanoff S, Klepp KI, Sjostrand J. Development of a health education program for elderly with age-related macular degeneration: a focus group study. Patient Education and Counseling 1998;34:63-73.

140 Van Zandt PL, Van Zandt SL, Wang A. The role of support groups in adjusting to visual impairment in old age. $\mathcal{F}$ Visual Impairment and Blindness 1994;88:244-52. 